\title{
Doğal Oksit Arayüzey Tabakalı Zr/p-Si Schottky Diyotlarının Yüksek Frekanslarda Kapasite-Gerilim ve İletkenlik-Gerilim Karakteristiklerinin Analizi
}

\author{
Durmuş Ali ALDEMIR ${ }^{1}$, Havva Elif LAPA ${ }^{2 *}$, Ahmet Faruk ÖZDEMİR ${ }^{1}$, Nazım UÇAR ${ }^{1}$

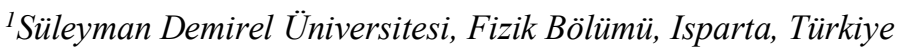 \\ ${ }^{2}$ Isparta Uygulamalı Bilimler Üniversitesi, Enerji Sistemleri Mühendisliği Ana Bilim Dalı, Lisansüstü Eğitim \\ Enstitüsü, Isparta, Türkiye \\ (ORCID: 0000-0003-4819-840X)(ORCID:0000-0002-5706-4641) \\ (ORCID:0000-0001-9879-9209)(ORCID:0000-0002-0936-0382)
}

\section{Öz}

Manyetik saçtırma yöntemiyle imal edilen $\mathrm{Zr} / \mathrm{SiO}_{2} / p$-Si Schottky diyotların kapasite-gerilim-frekans $(C$ - $V$ - $f)$ ve iletkenlik-gerilim-frekans $(G-V-f)$ ölçümleri $500 \mathrm{kHz}-3 \mathrm{MHz}$ aralığında 5 farklı frekansta ve oda sıcaklığında alınmıştır. $1 \mathrm{MHz}$ frekans için $C$ - $V$ karakteristiği yardımıyla arayüzey oksit tabakasının kalınlığı $2.33 \mathrm{~nm}$ olarak hesaplanmıştır. Güçlü birikim bölgesindeki $C$ ve $G$ değerleri kullanılarak seri direncin ortalama değeri $70.5 \Omega$ olarak elde edilmiştir. Bu diyotlar için, Hill-Coleman metodu ile hesaplanan arayüzey durum yoğunluğunun $\left(D_{i t}\right)$ artan frekansla azaldığı görülmüştür. Elde edilen bulgulara göre, $\mathrm{Zr} / \mathrm{SiO}_{2} / p-\mathrm{Si}$ Schottky diyotları hızlı anahtarlama için umut vaat edicidir.

Anahtar kelimeler: Schottky diyot, silisyum, kapasite-iletkenlik.

\section{The Analysis of Capacitance-Voltage and Conductance-Voltage Characteristics of $\mathrm{Zr} / p$-Si Schottky Diodes with a Native Oxide Interfacial Layer at High Frequencies}

\begin{abstract}
Capacitance-voltage-frequency $(C-V-f)$ and conductance-voltage-frequency $(G-V-f)$ measurements of $\mathrm{Zr} / \mathrm{SiO}_{2} / p$ $\mathrm{Si}$ Schottky diodes produced by magnetic sputtering technique were taken for five different frequencies $(500 \mathrm{kHz}-$ $3 \mathrm{MHz}$ frequencies range) at room temperature. The thickness of the interfacial oxide layer was calculated as 2.33 $\mathrm{nm}$ by means of $C-V$ characteristic for $1 \mathrm{MHz}$ frequency. The average value of series resistance was obtained as $70.5 \Omega$ by using $C$ and $G$ values in the strong accumulation region. For these diodes, it was observed that the interfacial state density $\left(D_{i t}\right)$ calculated by the Hill-Coleman method decreased with increasing frequency. According to the findings, the $\mathrm{Zr} / \mathrm{SiO}_{2} / p$-Si Schottky diodes are promising for fast switching.
\end{abstract}

Keywords: Schottky diode, silicon, capacitance-conductance.

\section{Giriş}

1874'te Braun'un bakır, demir ve kurşun sülfür kristal üzerine metalik nokta kontağın doğrultucu doğasını rapor etmesinden bu yana metal yarilietken kontaklar/Schottky diyotlar halen bilim insanları için araştırma konusudur. Schottky diyotlar, hızlı anahtarlama yetenekleri ve düşük doğru beslemlerde çalışabilmelerinden dolayı elektronik sanayinde güç algılama, karıştırma ve mikrodalga ağ devreleri gibi birçok uygulamada tercih sebebidir [1-3].

Yüksek performansa sahip kaliteli bir Schottky diyot yüksek engel yüksekliğine ve düşük sızıntı akımına sahip olmalıdır. Bu amaçla, $p$ tipi bir yariiletken ile düşük iş fonksiyonuna sahip nadir toprak

*Sorumlu yazar:h.eliflapa@gmail.com

Geliş Tarihi: 04.12.2019, Kabul Tarihi: 11.05.2020 
metalleri olarak adlandırılan $\mathrm{Yb}(2.60 \mathrm{eV}), \mathrm{Gd}(3.10 \mathrm{eV})$ ve $\mathrm{Er}(3.12 \mathrm{eV})$ gibi bir metal kontak haline getirilebilir [4-6]. Geçiş metalleri ya da valf metalleri olarak adlandırılan ve yüzeyinde doğal pasif oksit tabakası bulunduran $\mathrm{Al}$, Ti ve Zr gibi bazı metaller de kullanılarak üretilen metal yariiletken kontakların elektriksel karakteristikleri dikkat çekicidir [7-11]. Ti (4.33 eV) ve Al (4.28 eV) metallerine göre kısmen düşük iş fonksiyonuna sahip olan $\mathrm{Zr}(4.05 \mathrm{eV})$ metali aynı zamanda yüksek erime noktasına da sahiptir. Böylece, hem geniş engel yüksekliği ve düşük sızıntı akımı elde edebilmek hem de yarıiletkenler üzerinde kararlı elektrot sağlayabilmek amacıyla kullanılmaktadır [5,11]. Metal ve yarıiletken arasında yalıtkan/oksit bir tabakanın doğal olarak oluşturulması veya biriktirilmesi sızıntı akımı sorununu çözmek için bir alternatiftir. Ayrıca, arayüzeyde böyle bir tabaka kullanmanın metal ve yariiletken arasındaki difüzyon reaksiyonunu önlediği, yarıiletken yüzeyinde aktif sarkan bağları pasifleştirdiği ve engel yüksekliğinde artışa sebep olduğu bilinmektedir [12-14].

$\mathrm{Bu}$ çalışmada, görece düşük iş fonksiyonuna sahip olmasından dolayı $\mathrm{Zr}$ metali Schottky kontak elde etmek için kullanılmıştır. $p$-Si yarıiletken üzerinde oksit tabakanın doğal olarak oluşumu sağlanarak yukarıda bahsedilen özelliklere sahip bir diyot üretmek amaçlanmıştır. İmal edilen $\mathrm{Zr} / \mathrm{SiO}_{2} / p-\mathrm{Si}$ Schottky diyotların kapasite-gerilim-frekans $(C-V-f)$ ve iletkenlik-gerilim-frekans $(G-V-f)$ ölçümleri karanlıkta ve oda sıcaklığında alınmıştır. Nicollian-Brews yöntemi ile seri direnç $\left(R_{s}\right)$ değerleri elde edilirken Hill-Coleman metodu ile arayüzey durum yoğunlukları $\left(D_{i t}\right)$ hesaplanarak diyotların elektriksel karakteristikleri detaylı bir şekilde analiz edilmiştir.

\section{Materyal ve Metot}

$\mathrm{Bu}$ çalışmada kullanılan $p$-tipi Si yariletken alttaş [100] yönelimine ve $1 \Omega \cdot \mathrm{cm}$ özdirence sahiptir. $p$ tipi Si yariiletken alttaş organik ve inorganik kirlerden sslak kimyasal temizleme işlemi ile arındırılmıştır. $\mathrm{Bu}$ amaçla alttaş; asetonda $70{ }^{\circ} \mathrm{C}$ 'de $10 \mathrm{dk}$ kaynatıldı ve metanolde $5 \mathrm{dk}$ bekletildi. $\mathrm{NH}_{4} \mathrm{OH}+\mathrm{H}_{2} \mathrm{O}_{2}+5 \mathrm{H}_{2} \mathrm{O}(1: 1: 5)$ içerisinde $70{ }^{\circ} \mathrm{C}$ ' de $5 \mathrm{dk}$ ve $\mathrm{HCl}+\mathrm{H}_{2} \mathrm{O}_{2}+5 \mathrm{H}_{2} \mathrm{O}(1: 1: 5)$ içerisinde $70{ }^{\circ} \mathrm{C}$ 'de 10 dk kaynatıldı. \%2'lik sulu HF çözeltisi içerisinde $2 \mathrm{dk}$ bekletildi. Ardından, arka yüzeyine $200 \mathrm{~nm}$ kalınlıkta Al buharlaştırılarak $\mathrm{N}_{2}$ ortamında $575{ }^{\circ} \mathrm{C}$ 'de $3 \mathrm{dk}$ tavlandı ve böylece omik kontak yapıldı. Omik kısmı tamamlanan diyot, Si alttaşın ön yüzeyinde oksit tabakası oluşturmak amacıyla yaklaşık 6 ay boyunca hava ortamına maruz bırakıldı. Bu yapının ön yüzeyine $1 \mathrm{~mm}$ çaplarda dairesel deliklere sahip bir maske yerleştirildi ve manyetik saçtırma sisteminde $60 \mathrm{~nm}$ kalınlığında $\mathrm{Zr}$ buharlaştırılarak $\mathrm{Zr} / \mathrm{SiO}_{2} / p$-Si/Al Schottky diyotlarının üretimi tamamlandı. Şekil 1 'de $\mathrm{Zr} / \mathrm{SiO}_{2} / p-\mathrm{Si}$ Schottky diyotlarının yapısı şematik olarak gösterilmiştir.

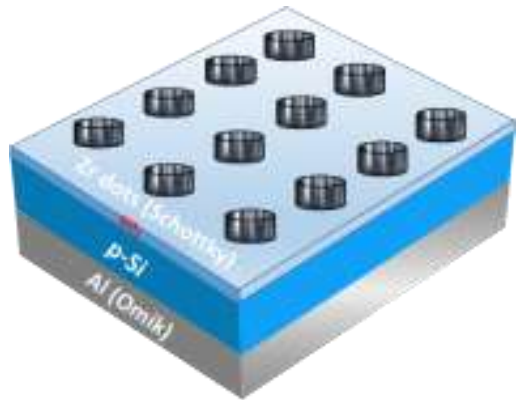

Şekil 1. $\mathrm{Zr} / \mathrm{SiO}_{2} / p$-Si Schottky diyotlarının şematik gösterimi

İmal edilen diyotun $C-V-f$ ve $G-V-f$ verileri $\pm 5 \mathrm{~V}$ gerilim ve $500 \mathrm{kHz}-3 \mathrm{MHz}$ frekans aralığında 4192A LF empedans analizörü kullanılarak ölçülmüştür. Tüm ölçümler karanlık ortamda ve oda sıcaklığında gerçekleştirilmiştir.

\section{Bulgular ve Tartışma}

Schottky diyotlarda kapasite-gerilim tekniği, diyota uygulanan voltaja bağlı olarak ölçülen kapasite değerlerine dayanmaktadır. İdeal durumda, bu aygitlara yeterince yüksek frekans $(f \geq 500 \mathrm{kHz})$ uygulanırsa kapasite değerinin uygulanan frekanstan etkilenmediği bilinmektedir. Ancak, metal ve yarıiletken arasında doğal olarak oluşan ya da depolanarak meydana getirilen bir oksit/yalıtkan tabakanın varlığı ve oksit/yalıtkan tabaka-yarniletken arayüzeyinde yerleşik yüklerin (arayüzey 
durumları/tuzakları) yer alması aygıtın ideal durumdan sapmasına yol açar. Aygita alternatif sinyal (AC) uygulandığında bu yükler tuzaklanabilir ya da salınabilir. Bu durum, uygulanan frekansla aygıtın kapasite ve iletkenlik değerlerinin değişmesine neden olur [12,15].

$\mathrm{Zr} / \mathrm{SiO}_{2} / p$-Si Schottky diyotlarının $C$ ve $G$ değerlerinin frekansa ve uygulanan beslem gerilimine bağlı olarak değiştiği görülmüştür (Şekil 2a-b). Kapasite değerleri azalan frekansla artarken iletkenlik değerleri artan frekans ile artmaktadır. Bu eğrilerin konumlarının değişmesi, yukarıda da belirtildiği gibi arayüzey durumları ile açıklanabilir. Yüksek frekanslar için arayüzey durumlarındaki yüklerin gevşeme zamanı periyottan $(T=1 / f)$ daha büyüktür. Bu sebeple, tuzaklardaki yükler AC sinyalini kolayca takip edemez ve ölçülen $C$ ve $G$ değerlerine katkı sağlayamaz. Bununla birlikte, düşük frekanslarda arayüzey durumlarının gevşeme zamanı periyottan daha kısadır. Bundan dolayı, arayüzey durumlarındaki birçok yük AC sinyalini kolayca izleyebilir. Yani düşük frekanslarda arayüzey durumları ek bir kapasite ve iletkenlik değeri verir $[12,14]$.
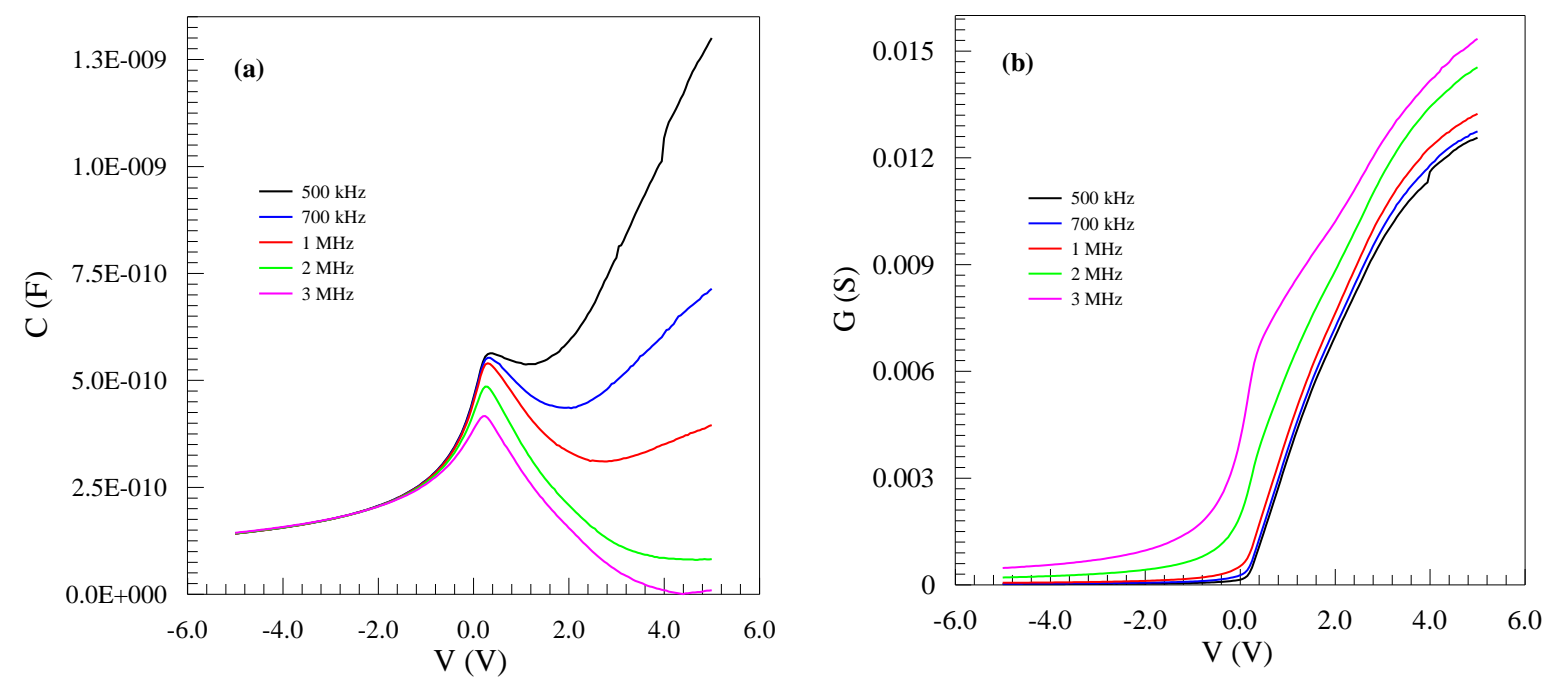

Şekil 2. $\mathrm{Zr} / p$-Si Schottky diyotlarında oda sıcaklığı ve farklı frekanslar için a) $C$ - $V$ karakteristikleri b) $G$ - $V$ karakteristikleri

$C$ - $V$ eğrilerinin, MOS yapılara benzer olarak birikim, tüketim ve terslenim bölgelerine sahip olduğu görülmektedir (Şekil 2a). Böylece, hava ortamına maruz bıraktığımız $p$-Si alttaş üzerine imal ettiğimiz diyotumuzda $\mathrm{Zr}$ ve $p$-Si kontak arayüzeyinde bir oksit tabakanın $\left(\mathrm{SiO}_{2}\right)$ oluştuğundan söz edebiliriz. Bu oksit tabakanın kalınlığı Schottky diyotlarda $C$-V karakteristiklerinin güçlü birikim bölgesindeki kapasite ölçümleri yardımı ile $C_{o x}=\varepsilon_{i} \varepsilon_{o} A / \delta_{o x}$ denklemi kullanılarak hesaplanabilir [12]. Burada, $C_{o x}, \varepsilon_{i}, \varepsilon_{o}, A$ ve $\delta_{o x}$, sirasıyla, uygulanan frekans için kapasitenin pik değeri, arayüzeyin dielektrik sabiti $\left(\mathrm{SiO}_{2}\right.$ için $\left.=3.9 \varepsilon_{o}[2]\right)$, boşluğun dielektrik sabiti $\left(=8.85 \times 10^{-14} \mathrm{Fcm}^{-1}\right)$, diyot alanı (bizim diyotumuz için $A=7.85 \times 10^{-3} \mathrm{~cm}^{2}$ ) ve arayüzey oksit tabakasının kalınlığıdır. Literatürde hava ortamına maruz bırakılan Si yüzey üzerinde doğal oksit tabaka kalınlığının 1.4-1.5 nm olduğu rapor edilmiştir [16-19]. Bizim çalışmamızda $\mathrm{SiO}_{2}$ tabakasının kalınlığı $1 \mathrm{MHz}$ frekans için bahsi geçen denklem yardımıyla 2.33 $\mathrm{nm}$ olarak hesaplanmıştır. Hesaplanan bu değerin literatürdeki değere yakın olduğu görülmektedir. Metal/yariletken arayüzeyinde oksit ya da yüksek dielektrikli yalıtkan tabaka varlığında diyot kapasitesinin arttığı bilinmektedir [4]. $C$ - $V$ eğrileri artan gerilimle yaklaşık 0.4 V'a kadar artmış ve bir maksimum değerden geçtikten sonra azalışa geçmiştir. Bu pikten sonra, kapasite 2 ve $3 \mathrm{MHz}$ için uygulanan gerilimin artması ile azalmaya devam ederken 500, 700 ve 1000 kHz'ler için bir minimumdan geçtikten sonra tekrar yükselişe geçmiştir (Şekil 2a). Düşük frekanslarda uygulanan sinyalden etkilenen arayüzey durumları sinyale cevabı reddedebilir ya da kabul edebilir. Bu sebeple, $C$ - $V$ eğrileri tüketim bölgesinde pik(maksimum) sergileyebilir. Pik pozisyonu ve değeri yarıiletkenin yasak band aralı̆̆ında $\mathrm{SiO}_{2} / p$-Si arayüzeyinde arayüzey durumlarının özel dağılımından, yavaş ve hızlı durumların varlığından etkilenmektedir $[12,14]$. Şekil 2a-b'de görüldüğü gibi, $C$ ve $G$ değerlerinin tüketim bölgesindeki değişimi, dış elektrik alan altında $\mathrm{SiO}_{2} / p$-Si arayüzeyindeki arayüzey durumlarının yeniden yapılanmasindan ve yeniden düzenlenmesinden kaynaklanabilir. Tersinim bölgesinde $C$ ve $G$ 'de ki 
değişime ise $R_{s}{ }^{\prime}$ nin etkisi sebep olabilir. Görüleceği üzere $R_{s} ; C$ ve $G$ ölçümleri üzerinde arayüzey tuzakları kadar etkili bir parametredir.

Yariiletkenin arkasına ideal bir omik kontağın yapılamaması, yarıiletkendeki yapısal kusurlar, kirlikler ya da diyottan ölçüm alabilmek için prob telinin diyota temasının kaliteli olmaması $R_{s}$ ' ye sebep olan faktörlerdir [12,20]. Güvenilir ve iyi performans sergileyen bir diyot elde edebilmek için bu faktörlerin etkisi diyot üretiminde ve ölçüm esnasında alınacak önlemlerle en aza indirilebilir. $R_{s}$ 'nin değerleri Nicollian-Brews yönteminden aşağıdaki eşitlik yardımı ile hesaplanabilir [12]:

$$
R_{S}=\frac{G}{G^{2}+(\omega C)^{2}}
$$

Bu denklemde, $\omega(=2 \pi f)$ açısal frekans, $C$ ölçülen kapasite ve $G$ ölçülen iletkenlik değerleridir. Şekil 3 'te, $\mathrm{Zr} / \mathrm{SiO}_{2} / p$-Si Schottky diyotlarının farklı frekanslar için $R_{S^{-}} V$ eğrileri gösterilmiştir. Buradan $R_{S}$ değerlerinin uygulanan frekansa ve beslem gerilimine bağl1lı̆̆ açıkça görülmektedir. $R_{s}$ eğrileri düşük frekanslarda yaklaşık olarak +1 V' da bir pik davranışı sergilerken, artan frekansla bu pik değeri hem azalan hem de voltaj ekseninde sağa doğru kayan bir davranış sergilemektedir. Piklerin büyüklükleri artan frekansla azalmıştır. $\mathrm{Bu}$ durum, arayüzey tuzaklarının $\mathrm{SiO}_{2} / p$-Si arayüzeyinde özel dağılımına ve arayüzey tuzaklarının uygulanan frekansla yeniden yapılanıp yeniden düzenlenmesine atfedilebilir. $\mathrm{Bu}$ pikler, arayüzey yüklerinin gevşeme zamanları nedeniyle düşük frekanslarda aktif yüzey ve dipol polarizasyonundan kaynaklanabilir ve ayrıca yük taşıyıcılarının ve yönlendirilebilir dipollerin, kafes kusurlarının veya safsızlıkların varlığından da oluşabilir [12].

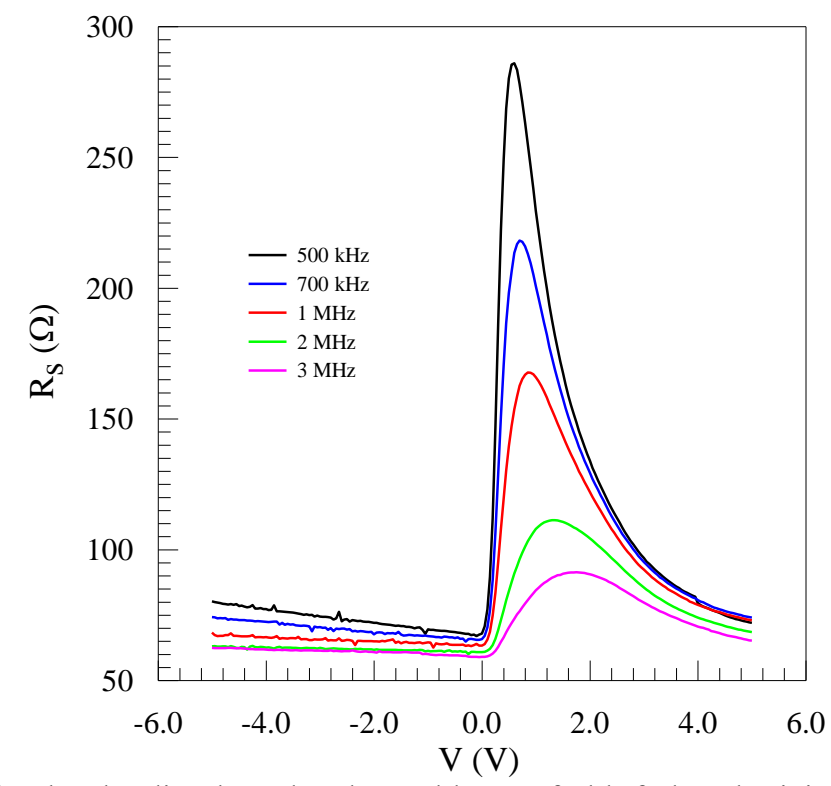

Şekil 3. $\mathrm{Zr} / \mathrm{SiO}_{2} / p$-Si Schottky diyotlarında oda sıcaklığ 1 ve farklı frekanslar için $R_{s^{-}} V$ karakteristikleri

Schottky diyotlar, yüksek frekanslarda bile hızlı çalışabilen diyotlardır. Schottky diyotların yüksek kesim (cutoff) frekansına $\left(f_{c}\right)$ sahip olması bu açıdan önemlidir $\left[f_{c}=\left(2 \pi R_{s} C_{F}\right)^{-1}\right]$ [21]. Bu nedenle, yüksek frekanslar için toplam seri direncin $\left(R_{s}\right)$ ve doğru beslem kapasitesinin $\left(C_{F}\right)$ düşük olması bir avantajdır. Şekil 2a ve Şekil 3'ten görüleceği gibi, $\mathrm{Zr} / \mathrm{SiO}_{2} / p-\mathrm{Si}$ Schottky diyotlarının yüksek frekanslarda düşük kapasite ve seri direnç değerlerine sahiptir. $\mathrm{Bu}$ durum, $\mathrm{Zr} / \mathrm{SiO}_{2} / p-\mathrm{Si}$ Schottky diyotlarının hızlı anahtarlamada kullanılması için umut vaat edici bir özelliktir. Ortalama seri direnç değeri ve sıfır beslemdeki kapasite değerinin kullanılmasıyla, kesim frekansı $5 \mathrm{MHz}$ olarak hesaplanmıştır.

Metal yariiletken kontaklarda ideal olmayan davranışların sebebi genellikle metal ve yariiletken arasında arayüzey tabakasının bulunmasına ve arayüzey hallerinin varlığına atfedilmektedir [22]. Bu nedenle, arayüzey hallerinin incelenmesi Schottky diyotların karakteristiğinin belirlenmesinde önem arz eder. $C$ - $V$ ve $G-V$ verileri yardımıyla arayüzey durumlarının yoğunluğu $\left(D_{i t}\right)$ Hill-Coleman metodu kullanarak elde edilebilir. Bu metot $D_{i t}{ }^{\prime}$ yi belirlemede hızlı ve güvenilir bir yöntemdir. Aynı zamanda bu yöntem arayüzeyin elektriksel performansının anlaşılmasına ve frekansın fonksiyonu olarak 
arayüzey durumlarının elde edilmesine imkân sağlar. Aşağıdaki eşitlik yardımıyla $D_{i t}$ değerleri hesaplanabilir [23]:

$D_{i t}=\frac{2}{q A} \frac{G_{\max } / \omega}{\left[\left(G_{\max } / \omega C_{o x}\right)^{2}+\left(1-C / C_{o x}\right)^{2}\right]}$

Bu denklemde, $A, \omega, q, C_{o x}, G_{\max }, C$, sırasıyla, diyot alanı, açısal frekans, elektrik yükü, $C$ - $V$ eğrisinin tersinim bölgesinde oksit tabakanın kapasitesi, $G-V$ eğrisinin maksimum değerine karşılık gelen iletkenlik değeri, $G_{\max }$ 'a karşıllı gelen kapasite değeridir. $\mathrm{Zr} / \mathrm{SiO}_{2} / p$-Si Schottky diyotları için $500 \mathrm{kHz}-$ $3 \mathrm{MHz}$ frekans aralığında elde edilen arayüzey durumları için yoğunluğun dağılımı Şekil 4 'te verilmiştir.

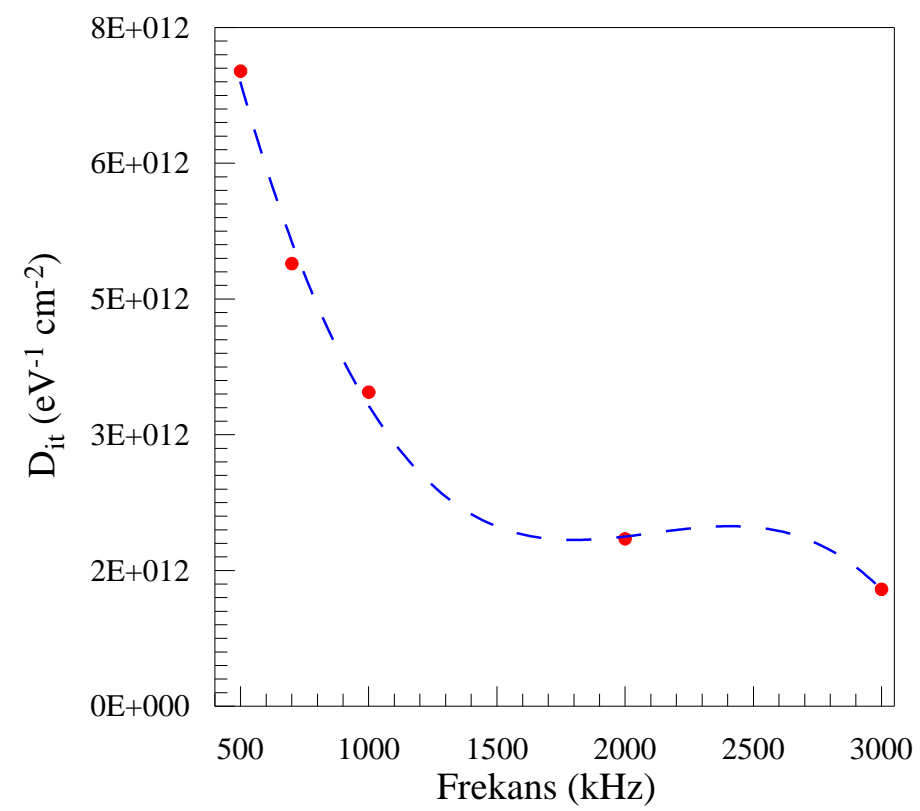

Şekil 4. $\mathrm{Zr} / \mathrm{SiO}_{2} / p$-Si Schottky diyotlarında oda sıcaklığında frekansa bağlı arayüzey durum yoğunluğu

Şekil 4'ten görüleceği gibi, arayüzey durumlarının yoğunluk değeri artan frekanslarla azalmaktadır. Arayüzey durumlarının yoğunluk değerinin bu davranışı, tuzaklardaki yüklerin AC sinyalini daha düşük frekanslarda takip edebilme kabiliyetinin bir sonucudur [14,23].

\section{Sonuç ve Öneriler}

Hava ortamına maruz bırakılan $p$-Si yarıiletkeni üzerine görece düşük iş fonksiyonuna sahip $\mathrm{Zr}$ metali fiziksel olarak buharlaştırılıp $\mathrm{Zr} / \mathrm{SiO}_{2} / p$-Si Schottky diyotları imal edilmiş̧ir. Doğal olarak elde edilen arayüzey $\mathrm{SiO}_{2}$ tabakasının kalınlığı $1 \mathrm{MHz}$ frekans için $C$-V karakteristiği yardımı ile $2.33 \mathrm{~nm}$ olarak hesaplanmıştır. $\mathrm{Zr} / \mathrm{SiO}_{2} / p$-Si Schottky diyotlarının ortalama $R_{s}$ değeri Nicollian-Brews yöntemi ile 70.5 $\Omega$ olarak hesaplanırken Hill-Coleman yöntemi ile elde edilen $D_{i t}$ değerlerinin $10^{12}$ mertebesinde olduğu ve frekansla değiştiği görülmüştür. Yüksek frekanslarda düşük kapasite ve seri direnç değerlerine sahip olan $\mathrm{Zr} / \mathrm{SiO}_{2} / p$-Si Schottky diyotları hızlı anahtarlama için umut vaat etmektedir.

\section{Teşekkür}

Bu çalışma Uluslararası Doğa Bilimleri Mühendisliği ve Malzeme Teknolojileri Konferansı-NEM 2019'da sözlü olarak sunulmuştur.

\section{Yazarların Katkısı}

D.A. Aldemir araştırma, doğrulama, inceleme ve düzenleme, kavramsallaştırma, metodolojiye katk1 sunmuştur. H.E. Lapa araştırma, orijinal taslak yazımı, kavramsallaştırma, metodolojiye katkı 
sunmuştur. A.F. Özdemir ve N. Uçar kaynak, materyal, malzeme temini, denetim, gözlem ve tavsiye konusunda katkı sunmuştur.

\section{Çıkar Çatışması Beyanı}

Yazarlar arasında herhangi bir çıkar çatışması bulunmamaktadır.

\section{Araştırma ve Yayın Etiği Beyanı}

Yapılan çalışmada, araştırma ve yayın etiğine uyulmuştur.

\section{Kaynaklar}

[1] Rhoderick E.H. 1982. Metal-Semiconductor Contacts. IEE Proceedings I Solid State and Electron Devices, 129 (1): 1-14.

[2] Neamen D.A. 2003. Semiconductor Physics and Devices: Basic Principles.McGraw-Hill, New York, 1-729.

[3] Su G., Yang S., Li S., Butch C.J., Filimonov S.N., Ren J.C., Liu W. 2019. Switchable Schottky Contacts: Simultaneously Enhanced Output Current and Reduced Leakage Current. Journal of the American Chemical Society, 141 (4): 1628-1635.

[4] Sze S.M., Kwok K.N. 2007. Physics of Semiconductor Devices. John Wiley and Sons, Canada, 1-815.

[5] Michaelson H.B. 1978. Relation between an Atomic Electronegativity Scale and the Work Function. IBM Journal of Research and Development, 22 (1): 72-80.

[6] Zhang Y.-Y., Jung S.-Y., Oh J., Shin H.-S., Oh S.-K., Wang J.-S., Majhi P., Jammy R., Lee H.D. 2010. Influence of Incorporating Rare Earth Metals on the Schottky Barrier Height of Ni Silicide. Japanese Journal of Applied Physics, 49 (5): 055701.

[7] Romanov R.I., Zuev V.V., Fominskii V.Y., Demin M.V., Grigoriev V.V. 2010. Electrical Properties of Thin-Film Structures Formed by Pulsed Laser Deposition of Au, Ag, Cu, Pd, Pt, W, Zr Metals on n-6H-SiC Crystal. Semiconductors, 44 (9): 1192-1198.

[8] Tan C.K., Abdul Aziz A., Hassan Z., Yam F.K., Lim, C.W., Hudeish A.Y. 2006. Pinning Fermi Level of p-GaN due to Three Different ( $\mathrm{Zr}$, Ti and Cr) Metal Contact. Materials Science Forum, 517: 262-266.

[9] Tan C.K., Abdul Aziz A., Yam F.K. 2006. Schottky Barrier Properties of Various Metal (Zr, Ti, $\mathrm{Cr}, \mathrm{Pt}$ ) Contact on p-GaN Revealed from I-V-T Measurement. Applied Surface Science, 252 (16): 5930-5935.

[10] Yamauchi T., Zaima S., Mizuno K., Kitamura H., Koide Y., Yasuda Y. 1990. Solid Phase Reaction and Electrical Properties in Zr/Si System. Applied Physics Letters, 57 (11): 1105-1107.

[11] Rajagopal Reddy V., Asha B., Choi C.-J. 2017. Schottky Barrier Parameters and Structural Properties of Rapidly Annealed $\mathrm{Zr}$ Schottky Electrode on p-Type GaN. Journal of Semiconductors, 38 (6): 064001.

[12] Nicollian E.H., Brews J.R. 1982. MOS (Metal Oxide Semiconductor) Physics and Technology, John Wiley and Sons, New York, 1-906.

[13] Lapa H.E., Kökce A., Al-Dharob M., Orak İ., Özdemir A.F., Altındal Ş. 2017. Interfacial Layer Thickness Dependent Electrical Characteristics of Au/(Zn-Doped PVA)/n-4H-SiC (MPS) Structures at Room Temperature. The European Physical Journal Applied Physics, 80 (1): 10101.

[14] Altındal Ş., Kanbur H., Yücedağ İ., Tataroğlu A. 2008. On the Energy Distribution of Interface States and Their Relaxation Time and Capture Cross Section Profiles in $\mathrm{Al} / \mathrm{SiO}_{2} / \mathrm{p}-\mathrm{Si}$ (MIS) Schottky Diodes. Microelectronic Engineering, 85 (7): 1495-1501.

[15] Rhoderick E.H., Williams R.H. 1988. Metal-Semiconductor Contacts. Clarendon Press, Oxford, $1-252$.

[16] Morita M., Ohmi T., Hasegawa E., Kawakami M., Ohwada M. 1990. Growth of Native Oxide on a Silicon Surface. Journal of Applied Physics, 68 (3): 1272-1281.

[17] Gräf D., Grundner M., Schulz R., Mühlhoff L. 1990. Oxidation of HF-Treated Si Wafer Surfaces in Air. Journal of Applied Physics, 68 (10): 5155-5161. 
[18] Graf D., Bauer Mayer S., Schnegg A. 1993. Influence of $\mathrm{HF}^{-} \mathrm{H}_{2} \mathrm{O}_{2}$ Treatment on $\mathrm{Si}(100)$ and Si(111). Journal of Alloys and Compounds, 74 (3): 1679-1683.

[19] Çetinkara H.A., Güder H.S. 2010. On the Effects of Air-Exposure-Time and Time-Dependency of $\mathrm{Pb} / \mathrm{p}-\mathrm{Si}$ Schottky Diodes.Physica B, 405: 4480-4487.

[20] Tecimer H., Uslu H., Alahmed Z.A., Yakuphanoğlu F., Altındal Ş. 2014. On the Frequency and Voltage Dependence of Admittance Characteristics of Al/PTCDA/p-Si (MPS) Type Schottky Barrier Diodes (SBDs). Composites Part B, 57: 25-30.

[21] Sharma B.L. 1984. Metal-Semiconductor Schottky Barrier Junctions and Their Applications. Plenum Press, New York and Londra, 1-370.

[22] Türüt A., Sağlam M. 1992. Determination of the Density of Si-Metal Interface States and Excess Capacitance Caused by Them. Physica B: Condensed Matter, 179 (4): 285-294.

[23] Hill W.A., Coleman C.C. 1980. A Single-Frequency Approximation for Interface-State Density Determination. Solid-State Electronics, 23 (9): 987-993. 